\title{
Gender impact on the learning organization
}

Simon Reese

\author{
University of Maryland University College, Seoul, The Republic of Korea
}

This issue of The Learning Organization journal exposes the topic of inclusion from a gender perspective and the impact of said inclusion on organizational learning. For a practitioner, the implications to business becomes increasingly clear through the reading of each article. Inclusion with a focus on gender has a positive bearing on exactly how an organization learns. Additionally, as various authors posit, prior organizational learning theories may overlook gender and thereby inadvertently downplay the impact of gender in the learning process. Re-looking at gender possibly will change the way we view organizational learning. And, with the industrialized economies having seen continual growth of women in the workforce over the past 60 years, a practitioner can ill afford to overlook the gender impact on organizational learning.

In an introduction to the four articles in this issue of The Learning Organization journal, Buzzanell (2018) provides readers an in-depth overview of the themes consistent throughout. As she summarizes, the common themes throughout touch upon "challenging commonsense, blurring boundaries between reality and imagined visions, and multilevel analyses and strategies for change". Starting with Buzzanell article provides practitioners with clear insights into what is to come within the issue. But, more directly to practice, the concluding section outlines details on both future research and practice. It is in this section that the author summarizes how to best accomplish success in light of the aforementioned common themes in the workplace.

In the first article of the themed series, Abrahamsson and Johansson (2018) provide practitioners a basis for adding the gender perspective into workplace learning. In their paper titled "Gender-equal organizations as a prerequisite for workplace learning", the authors analyze the organizational characteristics that promote both adoptive and developmental learning. In their emphasis on a gender-equal organization, the authors explore the research questions of: "in what way do gendered structures and notions effect workplace learning, and what characterize an organization where workplace learning would be hindered by gender structure and notions?". Implications appear throughout with compelling examples such as those originating from the impact of gender-based structures and notions. Practitioners can reflect upon their own understanding of gender impact on organizational learning and determine if they see gender structures and notions preventing developmental learning and restricting adoptive learning as the authors summarize. An instant implication for practice is the identification of existing gendered structures and notions in the workplace because if gender shapes interaction that impact success, it is the outcomes in the structures and notions that can be most easily identified. Then, upon

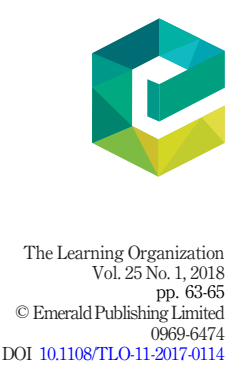


TLO

25,1

64

identification of the outcomes, leaders can double back to solve the underlying reason for the gender perception.

Bleijenbergh et al. (2018) expand more deeply into the gender neutrality of organizational learning in their article "The gender subtext of organizational learning". The authors employ gender subtext analysis to evaluate Argyris and Schon's theory of organization learning (1978) as they explore if the theory is rightly gender neutral. As the authors identify and not unusual for the time period of the theory design, Argyris and Schon's theory builds from white middle-class masculine interactions. However, the theory embraces both a masculine and feminine aspect through the interaction of the single-loop (masculine) and double-loop (feminine) learning. As the authors determine, the best implication to learnings is a balance of the masculine learning model I approach and the feminine learning model II approach. As a result, practitioners should cultivate methods of alternating the masculine and feminine based upon the context of the organizational problem. Further to managing the altering of perspectives, the authors propose that practitioners "extend the domains of organizational learning to the lower organizational echelons". Through both altering and expanding, practitioners can improve upon the theory of organizational learning as they implement a gender inclusive environment.

Brazil et al. (2018) in "Universities as inclusive learning organizations for women" also use former learning organization models to evaluate the gender question as they evaluate Senge's (1990) The Fifth Discipline to determine if the model fits in a higher education setting. The authors view women in faculty and academic leadership roles. They review each of Senge's five disciplines as they assess challenges and possibilities within each. In each of the five disciplines the authors highlight situations and areas of focus easily noticeable for practitioners in any setting. The authors conclude with some very clear next steps for practitioners to consider in the pursuit of making higher education a true learning organization. A true benefit of this paper is that the lucidity in each situation links to the five disciplines, and the notions throughout the paper can immediately apply in situations well beyond that of higher education as the authors examples apply well beyond the context of the article.

Lord et al. (2018) continue with the theme that prior organizational learning studies may have under-explored the impact of gender in their article "Unseen and unheard? Women managers and organizational learning". The authors outline the social construct of invisibility and the detrimental impact of invisibility on tacit knowledge. From an inclusive perspective, the authors highlight how gender impacts social perspective of learning and limits the interplay that results in learning. For practitioners, the implications are clear ensure everyone is involved in the conversation. To validate their findings, the authors utilized four semi-structured interviews with six women over a 12-month period. The women were chosen because they were part of a 24-person group with a peer-set of equivalent demographics. The results point directly to the changes that a practitioner can apply in group settings. Of utmost importance for the practitioner is ensuring that gender does not generate a platform for non-inclusion during critical moments as learning is cocreated. And, in generating a platform of inclusion, practitioners should appreciate that organizations are not gender neutral and any position of non-inclusion can greatly weaken the ultimate organizational outcome.

The book review in this issue of The Learning Organization may provide the most salient declarations for practitioners on inclusion and gender. As Natasa Rupcic outlines from the book "Learning in Organizations: Complexities and Diversities", "creation of knowledge in organizations takes place in the context of social relationships and within different forms of networks". As a practitioner, one takes on 
the responsibilities of ensuring a strong social context inclusive of all. With gender accounting for an almost equal dividing line in many industrialized workforces, a practitioner must remove the divides by ensuring we see all, hear all and include all in pushing the organization toward learning and success.

\section{References}

Abrahamsson, L. and Johansson, K. (2018), "Gender-equal organizations as a prerequisite for workplace learning”, The Learning Organization, Vol. 25 No. 1, pp. 10-18.

Bleijenbergh, I., Fokkinga, B., Raaijmakers, S. and Visser, M. (2018), "The gender subtext of organizational learning", The Learning Organization, Vol. 25 No. 1, pp. 19-28.

Brazil, A., Gouthro, P. and Taber, N. (2018), "Universities as inclusive learning organizations for women", The Learning Organization, Vol. 25 No. 1, pp. 29-39.

Lord, G., Martin, L. and Warren-Smith, I. (2018), "Unseen and unheard? Women managers and organizational learning”, The Learning Organization, Vol. 25 No. 1, pp. 40-50.

\section{Further reading}

Cozza, M., Gherardi, S. and Poggio, B. (2018), "Organizational members as storywriters: on organizing practices of reflexivity", The Learning Organization, Vol. 25 No. 1, pp. 51-62.

Rupcic, N. (2018), "Book review: learning in organizations: complexities and diversities", The Learning Organization, Vol. 25 No. 1, pp. 66-70.

For instructions on how to order reprints of this article, please visit our website: 